\title{
JACÓ, DE TRAPACEIRO A PATRIARCA, CAMINHOS DA INDIVIDUAÇÃO
}

\author{
Jacob, who was a Cheater and Became a Patriarch, \\ ways to Individuation
}

\author{
Flávio Luis Horlle ${ }^{1}$ \\ Nélio Pereira da Silva ${ }^{2}$
}

\section{Resumo}

Pesquisa bibliográfica que teve como objetivo apresentar o desenvolvimento pessoal do personagem bíblico Jacó com base na psicologia analítica de C. G. Jung. No primeiro capítulo, é apresentada uma relação entre Deus e o Si-mesmo, e Jacó e o ego, onde um paralelo é feito na medida em que Jacó precisa sair de casa e deixar a identificação que tinha com sua mãe. Neste capítulo também é definida a inflação do ego e se faz uma relação desta condição com o que os gregos chamavam de hybris e suas conseqüências. No segundo, o sonho de Jacó é analisado como um componente importante da jornada do herói, quando este se encontrava no deserto. No sonho há a primeira grande experiência de Jacó com o religioso, se faz uma relação aqui com algumas operações alquímicas. O terceiro capítulo marca a parte principal da trajetória de Jacó, quando este decide voltar para a casa dos seus pais e se reconciliar com seu irmão Esaú. No caminho, porém, há uma luta com Deus no vale do rio Jaboque que vai ser importante em termos de desenvolvimento pessoal. Jacó muda sua postura de vida, seus valores, passa pelo processo de individuação que influencia até na mudança de seu nome: agora ele não é mais Jacó, o "enganador", mas Israel, "aquele que luta com Deus". Volta então para casa e se reconcilia com seu irmão, fechando um ciclo importante de vida. Dessa forma, o estudo da vida de Jacó se torna arquetípico para se entender o desenvolvimento pessoal e o processo de individuação, notadamente do homem.

Palavras-chave: Inflação; Individuação; Hybris; Arquétipo.

1 Pastor Luterano, Psicólogo, Pós-graduado em Psicologia Analítica na Pontifícia Universidade Católica do Paraná, Av. Pátria, 631, 90.230-071, Porto Alegre, RS, flavio@comcristo.org.br

2 Professor de Psicologia Analítica da Pontifícia Universidade Católica do Paraná, Psicólogo, Orientador do trabalho. 


\section{Abstract}

Bibliographycal research work with the objective of presenting the personal development of Jacob, the Biblical character, based on the analytical psichology of C.G.Jung. In the first chapter a relationship of God with Self is described and then of Jacob and his ego. A parallel is drawn as to Jacob having to leave his home and the idenfication he had with his mother. In this chapter the inflating of his ego is defined and a relationship of this condition is made with what the Greek called "hybris " and its consequences. In the second chapter, Jacob's dream is analyzed as an important component of the hero's journey when he wandered in the desert. The first great experience of Jacob with religiousness is found in this dream and a relationship with alchemistical operations, also. The third chapter establishes the main part of Jacob's plight, when he decides to return to his parents' home and seek reconcilement with his brother Esau. On the way back though Jacob wrestles with God in the valley of the river Jabbok and this experience would be very important for the development of his personality. Jacob changes his attitude towards life and its values. He goes through a process of individuaatioin that will influence him even in the changing of his name: he is no longer Jacob the "cheater" but Israel "the one who wrestles with God". He returns home and becomes reconciled with his brother thus closing and important cicle of his life. In this way, the study of the life of Jacob becomes an archtype to understand the development of one's self and the process of individuation, in especial, of man.

Keywords: Inflation; Individuation; Hybris; Archetype.

\section{Introdução}

Por mais estranho que possa parecer, é necessário colocar que este trabalho não é e é, ao mesmo tempo, de cunho religioso.

Não é na medida em que trata de um tema em psicologia junguiana, que é a individuação. Isto colocado fica clara a analogia que se faz aqui de Jacó e seu desenvolvimento pessoal com o ego em relação ao Si-mesmo.

Por outro lado, de certa forma tem seu cunho religioso, pois Jung via na religião paralelos interessantes com o processo de individuação, por ser a religião uma manifestação genuína do inconsciente coletivo, e não simplesmente um agrupamento de conteúdos reprimidos, como sugeria Freud.

Para maior clareza, sugere-se a leitura dos capítulos 25 a 35, do livro de Gênesis, da Bíblia Sagrada (2000).

No primeiro capítulo, é apresentada uma relação entre Deus e o Si-mesmo, e Jacó e o ego, onde um paralelo é feito na medida em que Jacó precisa sair de casa e deixar a identificação que tinha com sua mãe. Neste capítulo também é definida a inflação do ego e se faz uma relação desta condição com o que os gregos chamavam de hybris e suas conseqüências.

No segundo, o sonho de Jacó é analisado como um componente importante da jornada do herói, quando este se encontrava no deserto. No sonho há a primeira grande experiência de Jacó com o religioso, se faz uma relação aqui com algumas operações alquímicas.
O terceiro capítulo marca a parte principal da trajetória de Jacó, pois ele passa pelo processo de individuação que se manifesta até na mudança de seu nome: agora ele não é mais Jacó, o "enganador", mas Israel, "aquele que luta com Deus". Volta então para casa e se reconcilia com seu irmão, fechando um ciclo importante de vida. Dessa forma, o estudo da vida de Jacó se torna arquetípico para se entender o desenvolvimento pessoal e o processo de individuação, notadamente do homem.

\section{Partida e jornada}

Qual o pior pecado que pode ser cometido por um ser humano?

Pecado aqui pode ser definido ou entendido como uma ofensa aos deuses ou, pior ainda, quando o ser humano credita a si poderes e possibilidades como se ele fosse Deus, indo além dos seus limites.

Jung forneceu instrumentos na sua psicologia que permitem entender ou lidar com as implicações desta definição de pecado quando falou em Ego Inflado. Edinger (1972, p. 27 e 88) dá uma definição muito interessante do que seria esta situação quando diz:

A definição apresentada no dicionário para Inflação é: cheio de ar, dilatado pela ação do ar, irrealisticamente amplo e importante, além dos limites das próprias medidas; portanto, 
vaidoso, pomposo, orgulhoso, presunçoso. Uso o termo inflação para descrever a atitude e o estado que acompanham a identificação do ego ao Si-mesmo. Trata-se de um estágio no qual algo pequeno (o ego) atribui a si qualidades de algo mais amplo (Si-mesmo) e, portanto, está além das próprias medidas. (...) Pecado é a presunção inflada do ego, que assume as funções do Si-mesmo.

Jung, por sua vez, em $\mathrm{O}$ eu e o inconsciente se refere a este estado de inflação envolvendo "uma expansão da personalidade, além dos limites individuais ou, em outras palavras, uma presunção. Em tal estado, a pessoa ocupa um espaço que normalmente não pode preencher". (Jung, 1996, p. 227).

Definido o pecado, torna-se necessária uma reflexão sobre Deus, ou melhor, da representação de Deus na psicologia analítica. Não se quer aqui entrar numa discussão teológica, mas o objetivo desta definição é a possibilidade de um paralelo entre fenômenos simbólicos que acontecem na relação com Deus, com a relação com o Simesmo e o próprio inconsciente como um todo.

A proposição central do conceito junguiano de Deus é que Deus é um arquétipo (Palmer, 1997, p. 160). O próprio Jung (1994, p. 14) coloca esta questão em Psicologia e alquimia:

Quando digo, na qualidade de psicólogo, que Deus é um arquétipo, refiro-me ao "tipo" na psique. A palavra "tipo" é, como se sabe, derivada de typos, "golpe" ou "marca"; assim, um arquétipo pré-supõe um agente que faz a marca....Simplesmente não conhecemos a derivação última do arquétipo, não mais do que sabemos a origem da psique.

O Si-mesmo, por sua vez, pode ser entendido como o centro ordenador e unificador da psique total (consciente e inconsciente), assim como o ego é o centro da personalidade consciente. Outra forma de se expressar seria se pensar no ego como a sede da identidade subjetiva, pessoal, e o Si-mesmo como a sede da identidade objetiva, referente aos conteúdos do Inconsciente. O Simesmo, portanto, constitui um tipo de autoridade suprema, mantendo o ego submetido ao seu domínio. O Si-mesmo é descrito como a divindade empírica interna e equivale a imagem de Deus, a imago Dei (Edinger, 1972, p. 22).
Para se entender melhor o que seria esta imago Dei, Grinberg (1997, p. 157) em Jung - O homem criativo dá a seguinte explicação:

Jung chamou de Si-mesmo ou Self a esse arquétipo do "Deus-homem interior". Segundo ele, Deus é um conceito, definido como imago Dei, ou seja, é uma idéia dotada de extremo valor psicológico existente dentro de cada um de nós. Trata-se de uma imagem psíquica da totalidade transcendente do ser humano. O objeto que recebe a imagem projetada do Si-mesmo adquire poderes sobrenaturais. É assim que ocorrem as idolatrias e idealizações. Com esse arquétipo, endeusamos teorias, sistemas religiosos, a figura de um professor, analista, médico, mulher, criança, político, cantor de rock, esportista, animal de estimação, assim como dinheiro, poder, máquinas, carro ou computador. Assim, Deus pode ser adorado sob muitos aspectos: "O homem é livre para decidir se Deus será um espírito ou um fenômeno natural, como o apego de um viciado à morfina" (Psicologia e religião, p.142).

Para Jung, parece não ser possível distinguir empiricamente o arquétipo-Deus do arquétipo do Si-mesmo. Assim, em Mysterium coniunctionis (1997, p. 546), ele escreve:

A dificuldade extraordinária manifesta nessa experiência (do Si-mesmo) é que o Simesmo só pode ser distinguido conceitual, mas não praticamente, daquilo a que sempre se fez referência pela designação "Deus". Ambos os conceitos se apóiam aparentemente num fator numinoso idêntico que é uma condição de realidade.

A questão, porém, não é assim tão simples. Admitir essa identidade entre Deus e o Si-mesmo causa muita confusão e muito esforço já foi feito no sentido de deixá-la clara. A mais importante evidência disponível sobre o assunto está na série de cartas escritas por Jung ao teólogo católico Gebhard Frei. Frei revela a sua preocupação com o fato de Jung ter substituído Deus pelo Si-mesmo, uma conclusão que levou a uma resposta veemente de Jung. Escrevendo em setembro de 1944, replicou: 
Fiquei atônito ao ver que mesmo você não compreendeu o conceito do "self". De onde você tirou a idéia de que eu poderia substituir Deus - e com um conceito desses? Posso estabelecer a existência da integralidade psicológica a que se subordina a nossa consciência, integralidade que se acha, em si mesma, além da descrição precisa. Mas esse "self" nunca pode tomar o lugar de Deus, embora possa, quem sabe, ser um receptáculo para a graça divina. Essas lamentáveis compreensões errôneas do pressuposto de que sou um homem irreligioso que não acredita em Deus, e a quem se deve mostrar o caminho da fé (Palmer, 1997, p. 193).

Torna-se evidente que a posição de Jung de fato não é clara, observando uma outra carta, escrita em 1948, é possível se entender as críticas de Frei:

Eu poderia dizer que o "self" é de certo modo equivalente a Deus. A uma mente teológica tal asserção tem, sem dúvida, de ser perturbadora, visto que soa como se tivesse inventado algum substituto de Deus. Mas a um psicólogo essa interpretação parece igualmente absurda, e ele mal pode acreditar que alguém seja capaz de cometer tamanha estupidez. Eis como compreendo o assunto: quando (como psicólogo) falo de "Deus", refiro-me a uma imagem psicológica. Do mesmo modo, o "self" é uma imagem psicológica da integralidade humana, e o é também de algo transcendental - por ser indescritível e incompreensível. Observamos que um e outro se exprimem por símbolos idênticos ou que assemelham a ponto de ser indistinguíveis. A psicologia lida com essas imagens somente na medida em que são parte da nossa experiência, sua formação e seu comportamento no contexto da vida podem ser estudados por meio de métodos comparativos. Isso nada tem a ver com Deus enquanto tal. Como poderia algum homem sadio supor que pode tirar o lugar de Deus ou fazer qualquer coisa com ele? Não sou louco a ponto de se poder suspeitar que pretenda criar um substituto para Deus. Como pode algum homem substituir Deus? (Palmer, 1997, p. 193).

A partir destas definições de termos, é possível traçar um paralelo com Jacó e sua relação com Deus, e o ego com o Si-mesmo, rumando para a individuação.
A história de Jacó já começa de forma diferenciada. A sua mãe, Rebeca, não podia ter filhos, então seu pai, Isaque, intercede junto a Deus por esta situação.

Observa-se aqui uma posição muito bem definida e delimitada entre um eu e um tu, com a divindade. Há um respeito e uma crença efetiva no fato que esta divindade tem poder e pode interferir nos destinos dos seres humanos.

Após o pedido, o milagre acontece: Receba fica grávida, mas há algo incomum nesta gravidez, ou seja, as crianças que ela está esperando estão lutando em seu ventre.

Se estivesse no campo da racionalidade, Rebeca quem sabe poderia procurar algum tipo de explicação lógica para esta luta na sua barriga, mas, seguindo o que aprendera e a própria tradição na qual está inserida, foi consultar a Deus o motivo do que estava acontecendo.

A resposta de Deus, como normalmente acontece em se tratando de oráculos, não é clara, somente vai ser entendida completamente depois da sua realização. Deus diz: "no seu ventre há duas nações, você dará à luz dois povos inimigos. Um será mais forte do que o outro, e o mais velho será dominado pelo mais moço" (Gn 25.23).

Os meninos então nascem, o mais velho, Esaú, vai se tornar o preferido do pai. O mais novo, Jacó, vai ser o preferido da mãe.

Um detalhe no nascimento que não pode ser deixado de lado e que também tem seu aspecto profético é o fato de Jacó ter nascido segurando o calcanhar de Esaú. Poderia se pensar no calcanhar de Aquiles, que era o seu ponto fraco. Também um paralelo existe na sabedoria popular quando se usa a expressão "pegar no pé", como indicativo de que alguém está incomodando ou prejudicando um outro. Ou seja, somente este detalhe poderia ser ilustrativo para se entender a relação destes irmãos. Esta relação já aqui prometia ser complicada e até porque não dizer turbulenta.

Tendo em mente o oráculo e a necessidade de se aceitá-lo como uma determinação efetiva da vontade de Deus, o que seria de se esperar?

Naturalmente Rebeca, que preferia seu filho Jacó, e o próprio Jacó, poderiam esperar as coisas tomarem o rumo já determinado, pois, afinal, quem pode ir contra ou, de alguma forma, tomar o lugar de Deus? 
Ao contrário, em vez de esperar, dão a entender que é preciso agir, fazer alguma coisa para que a profecia se cumpra. Deus, por si, parece demorado e até de certa forma incompetente. Soma-se a isso o fato de Isaque notadamente preferir Esaú e estar disposto a passar sua bênção ao filho preferido. Jacó e Rebeca então assumem o papel de Deus em dois momentos para tentar garantir que as coisas de fato iriam acontecer como queriam ou como o previsto pelo próprio Deus.

Num primeiro momento, Jacó, aproveitando o cansaço e a fome do irmão Esaú e, utilizando grande astúcia, compra-lhe o direito de primogenitura, o direito especial que tinha o filho mais velho na cultura judaica, por um prato de lentilhas.

Num segundo momento, novamente a astúcia vai estar presente quando Rebeca e Jacó enganam o velho e cego Isaque, usando pele de carneiro, roupas de Esaú e um assado, fazendo com que este acabe abençoando Jacó, em vez de Esaú.

Pode-se fazer um paralelo com o que os gregos temiam sobremaneira, aquilo a que davam o nome de hybris, ou seja, a violência ou a paixão voluptuosas que emergem do orgulho (Edinger, 1972, p. 57). Ela poderia ser identificada com o que se define como estado de inflação do ego, a arrogância humana que se apropria daquilo que pertence aos deuses, ou seja, ir além dos limites humanos.

A tensão que vai existir aqui é a passividade em aceitar os desígnios dos deuses, o que poderia sugerir um determinismo, e o grau de responsabilidade que o ser humano tem sobre a sua própria vida.

A hybris é um crime, mas, quando se pensa na necessidade do desenvolvimento humano, ela passa a ser um crime necessário, como diz Edinger (1972, p. 50): "é preferível ser consciente a permanecer no estado animal. Mas, para emergir, o ego é obrigado a colocarse contra o inconsciente de que proveio e a assegurar sua autonomia com um ato inflado". Sem este crime de se procurar ultrapassar as medidas, sem a ousadia de se tentar superar velhos conceitos e paradigmas, não haveria avanço ou desenvolvimento.

\section{Um sonho}

A atitude de Jacó de enganar o seu irmão naturalmente gerou um estado de tensão entre eles. A Bíblia declara, nesse sentido, que Esaú ficou com ódio mortal de seu irmão, o que obrigou Jacó a fugir para escapar da vingança. Na primeira noite da fuga, Jacó tem um sonho numinoso.

Conforme já mencionado, houve um crime, no caso, o roubo de Jacó, e este crime implica naturalmente num preço ou ressarcimento que precisa ser feito ou pago.

Quando se leva em consideração os sentimentos que acompanhavam Jacó naquele momento delicado de vida, onde havia real possibilidade de ser morto pelo seu irmão Esaú, Myron Gubitz, citado por Edinger (1990, p. 69), fornece uma produtiva reflexão:

Em termos psicológicos, a ansiedade a respeito da violência ou destruição eminente (em caso extremo a paranóia) geralmente está ligada a profundo sentimento de culpa. Freqüentemente, também, essa culpa é o outro lado de uma inflação psíquica, de uma superioridade com um arquétipo poderoso. $\mathrm{Na}$ história mítica do povo judaico ambos fatores podem ser rastreados na ruptura entre Jacó e Esaú, e posteriormente, através dos tempos, na ramificação mítica de Amalec. A culpa na psique judaica coletiva é o preço inevitável pago pelo roubo que Jacó-Israel fez do direito de primogenitura de Esaú, por sua fraudulenta aquisição da bênção paterna, e por sua rejeição consciente dos aspectos e valores incorporados por Esaú.

Sobre a fuga de Jacó, é possível fazer um paralelo com o que Campbell, citado por Judy, descreve como padrão fundamental da história do herói tal como se encontra na mitologia e nas escrituras da religião de todo o mundo (Judy, 1992 p. 28).

O ciclo inicia-se com o chamado à aventura. Nesse momento, o herói é convidado a afastar-se de sua existência comum. Essa situação vai ser observada justamente na fuga de Jacó de sua terra. O herói começa uma jornada por um novo território onde há uma série de desafios a serem vencidos. É preciso abrir mão, deixar algo para trás e seguir para importantes lutas e conquistas. 
Continuando nessa perspectiva da jornada do herói, quando este se lança na aventura, vão existir tanto provas como auxiliares, como comenta Judy (1992, p. 29), "vemos que um dos grandes auxiliares de Jacó foi o sonho/visão noturna em que anjos sobem e descem por uma escada. Jacó sabe que seu auxiliar essencial divino está com ele". Sabedor de que Deus está com ele, Jacó vai ter a força necessária de continuar em frente.

A partir dessas considerações iniciais, é possível agora destacar aspectos que podem ser observados na experiência que Jacó teve com seu sonho.

Inicialmente, chama a atenção o fato de que Jacó estava em viagem pelo deserto, à noite, depois de um dia cansativo e chega a um lugar que a Bíblia chama de "lugar sagrado".

Caso se leve em consideração algumas variáveis, como: o seu estado emocional, potencializado pela culpa e pelo medo de ser morto por Esaú; um dia bastante cansativo de peregrinação pelo deserto; o fato de estar completamente sozinho, entregue aos seus próprios pensamentos; e finalmente, um lugar sagrado, era de se esperar que alguma coisa muito marcante poderia acontecer.

Em outras palavras, diante de fatores que favoreceram um rebaixamento da consciência, uma manifestação especial do inconsciente, ou do Simesmo, ou de Deus, certamente iria ter o seu lugar.

Jung (1965, p. 11), em Psicologia e Religião, destaca aspectos de uma experiência religiosa, que foi o que Jacó experimentou no deserto:

A religião, como denota a palavra latina, é uma cuidadosa e escrupulosa observação daquilo que Rudolf Otto denominou com precisão o numinosum, isto é, um agente ou efeito dinâmico que não é causado por um ato arbitrário de vontade. Pelo contrário, ele se apossa do sujeito humano, que é sempre antes vítima do que seu criador, e o controla. O numinosum qualquer que possa ser a sua causa - é uma experiência do sujeito que independe de sua vontade. Seja como for, tanto o ensinamento religioso como o consensus gentium explicam, sempre e em toda parte, essa experiência como decorrente de uma causa exterior ao indivíduo. O numinosum é tanto uma qualidade pertencente a um objeto visível como a influ- ência de uma presença invisível que provoca uma alteração peculiar da consciência. Essa é, de todo modo, a regra geral.

Pelo que pode ser notado até aqui, este prelúdio de tudo o que aconteceu antes do sonho propriamente dito vai fornecer dados para o que pode ser identificado como um estado de alienação do ego.

No estado de inflação que Jacó se mostrou possuído, era impossível uma experiência com Deus como algo real, como uma relação eu-tu, visto que ele inconscientemente estava identificado com Deus. Essa situação precisa ser seguida de uma experiência de alienação, de uma efetiva quebra do eixo ego-Si-mesmo, que naturalmente traz ao ego uma experiência de sofrimento e solidão, como uma preparação para a experiência religiosa. Surge daí a típica frase: "noite escura do espírito que precede a experiência religiosa" (Edinger, 1972, p. 85).

Seguindo a mesma linha de pensamento, Jacó precisava perder a sua identificação com Deus, ou seja, sua inflação, sua onipotência, sua ilusão de que por si poderia "dar um jeito em tudo", não necessitando de Deus, em última análise, sendo o seu próprio Deus, para então de fato reconhecer e encontrar Deus como um outro. Em outras palavras, enquanto estivesse identificado com Deus, Jacó não poderia experimentar a Sua existência.

Já que se observa a importância do eixo ego-Si-mesmo no processo de desenvolvimento de Jacó, torna-se interessante uma definição do que seria este eixo. Nesse sentido, Edinger (1972, p. 66) coloca:

O eixo ego-Si-mesmo representa a conexão vital entre o ego e o Si-mesmo, a qual deve ficar relativamente intacta se se pretende que o ego suporte as tensões e cresça. Esse eixo é uma passagem ou canal de comunicação entre a personalidade consciente e a psique arquetípica. A danificação do eixo ego-Simesmo impede e destrói a conexão entre consciente e inconsciente e provoca a alienação do ego com relação a sua origem e fundamento.

Voltando à narrativa bíblica, Jacó pegou uma pedra como travesseiro e começou a sonhar. No seu sonho, viu uma escada que ia da terra ao céu, e os anjos de Deus subiam e desciam por ela. 
A escada do sonho de Jacó vai ter duas implicações importantes, quando se pensa no seu simbolismo: o eixo ego-Si-mesmo e os procedimentos ou operações alquímicas de sublimatio e coagulatio.

Ainda sobre o eixo ego-Si-mesmo vale a pena assinalar que Jacó passou por um processo de inflação, em seguida de alienação e agora é apresentada uma cena preparatória da grande coniunctio que vai acontecer no episódio da luta com Deus. A escada é o eixo ego-Si-mesmo como um funcionamento saudável da psique.

Uma analogia interessante que Edinger (1972, p. 353) faz é comparar a escada com um cordão umbilical. Nessa perspectiva, é possível se pensar no processo de desenvolvimento do ego, a partir do seu estado inicial de completa identificação com o Si-mesmo. Palmer (1997, p. 189) explica com clareza os estágios do desenvolvimento do ego quando pontua:

No nascimento, não há um ego, mas uma completa identificação com o Self, isto é, com um estado de integralidade e de perfeição inconsciente. Nesse ponto, não podemos diferenciar entre nós e o mundo do inconsciente coletivo que é a nossa origem: encontramonos, por assim dizer, imersos nas imagens dos arquétipos e por isso, muito naturalmente, vemo-nos a nós mesmos, de maneira deveras literal, como o centro do universo - uma condição que, incidentalmente, pode continuar para além da infância e causar graves psicoses. Essa condição não pode, contudo, persistir por muito tempo. À medida que a realidade se impõe, o ego e o Self vão se alienando um do outro e vemos as primeiras indicações apreciáveis de uma personalidade do ego ora emancipado da psique coletiva, separação mais bem ilustrada pela agressividade e pela auto-afirmação da adolescência. Isso, porém, é igualmente apenas um estágio a ser superado, e a experiência da alienação é um prelúdio necessário a uma redescoberta do Self. Porque, cada vez mais, a alienação egoSelf produz um estado de falta de sentido que só pode ser levado a termo mediante o restabelecimento do vínculo que liga o ego e sua origem suprapessoal e coletiva.

Pensando na escada como cordão umbilical, a mãe como Si-mesmo primordial, tal escada pode ser uma prefiguração sobre o restabelecimento do eixo Ego-Si-mesmo que iria acontecer por ocasião da luta de Jacó com Deus.

Uma segunda implicação da escada seria a sua relação com as operações alquímicas de coagulatio e sublimatio.

A coagulatio diz respeito ao elemento terra, em transformar coisas em algo sólido. É possível se pensar também na concretização ou realização pessoal de uma imagem arquetípica (Edinger, 1972, p. 350).

Aplicando estas idéias à vida de Jacó, observa-se que este sonho marca uma caminhada, até aqui, em termos de desenvolvimento. Ao iniciar sua jornada, ele teve que trabalhar a coagulatio em si, ou seja, como diria a sabedoria popular, teve que efetivamente "colocar os pés no chão".

A sublimatio, por sua vez, vai ser o processo de elevação de experiências concretas e pessoais em nível superior, ou nível de verdade abstrata ou universal (Edinger, 1972, p. 350). Segundo Edinger, o grande perigo seria uma dissociação com a realidade.

Na vida de Jacó, esta justamente vai ser a primeira grande experiência com o divino, onde, além dos anjos subindo e descendo, ele ouve a vOz do próprio Deus prometendo bondade para com os seus descendentes e estar com ele por onde fosse. É de certa forma repetida aqui a promessa que foi feita antes do nascimento de Jacó.

$\mathrm{O}$ fato de os anjos estarem subindo e descendo nos remete a um detalhe importante da obra alquímica, a saber, que ela é Deo concedente, Deus a concede a quem ele quer, não é para qualquer um, como Jung (1994, p. 386; 423) coloca, citando a Introdução à Arte, dada por Morienus a Calid:

Esta coisa que há tanto tempo procuras não pode ser conquistada ou realizada à força, ou com paixão. Ela só é conquistada ou realizada pela paciência e humildade e através do amor decidido e perfeito. É que Deus concede esta ciência divina e pura a seus fiéis servidores, àqueles a quem Ele decidiu concedê-la desde o estado primordial das coisas (...) Eles (os eleitos) também não conseguiram reter coisa alguma a não ser pela força concedida por Deus, nem podiam dirigir suas mentes a não ser para a meta, que Deus lhe havia fixado. E isto porque Deus encarrega dentre os seus servidores aqueles que esco- 
lheu para esta intenção no sentido de procurarem essa ciência divina, oculta aos homens, e de preservá-la em si mesmos. Todos concordam desde os tempos mais remotos que sua Arte é sagrada e divina e que sua obra só pode ser levada a cabo mediante a ajuda de Deus. Esta ciência só é dada a poucos e só é entendida por aqueles a quem Deus ou mestre abriu o entendimento.

\section{Encontros}

Neste momento da vida de Jacó, ele pode ser encontrado como um homem maduro, depois de ter ficado 20 anos trabalhando com seu tio Labão, que resolve voltar para a sua terra e lidar com algumas questões que haviam ficado pendentes na sua história pessoal.

Levando em consideração a idade que ele tinha, provavelmente 40 anos, é possível imaginar que algo importante está acontecendo naquele momento de vida em termos de desenvolvimento pessoal. Palmer (1997, p. 188) tece algumas considerações sobre esta passagem da primeira para a segunda metade da vida:

Assim como a primeira metade da vida é marcada pela iniciação na realidade externa, assim também a segunda o é pela iniciação na realidade interna. Aqui, a preocupação anterior com alvos materiais e alcançáveis ganhar dinheiro, criar uma existência social e uma família - cede lugar a um conjunto distinto de prioridades. Fazem-se agora interrogações filosóficas e espirituais acerca do significado da vida e do propósito da existência. É comum que essa mudança dramática de atitude seja precipitada pela chamada "crise da meia-idade". Por volta da metade da vida, as energias físicas decrescem, há menos oportunidades de sucesso, as ambições juvenis foram realizadas ou abandonadas e as velhas convicções ou princípios morais já não são considerados apropriados às atuais necessidades. Isso faz com que o indivíduo experiencie um sentido de vazio e inadequação. Essa perda de valor - ou deslocamento de energia psíquica - proporciona, contudo, o ímpeto para uma transformação psicológica fundamental. Em sua busca de significação, a pessoa volta-se agora para dentro de si mesma e dá início a um auto-exame dos aspectos de sua natureza que foram, na luta pela sobrevivência, implacavelmente reprimidos. Em outras palavras, tem-se de descobrir um novo sentido e propósito de vida mediante a criação de um vínculo entre os aspectos conscientes e inconscientes da psique, por meio de percepção, de um lado, daquilo que é pessoal ao indivíduo e, de outro, daquilo que liga $\mathrm{o}$ indivíduo à forma coletiva da humanidade.

A história começa com Jacó deixando a casa do tio-sogro Labão, colocando-se a caminho da casa de seus pais, agora não mais como um simples pastor de ovelhas, mas como um homem rico. Ele mesmo constata isso quando comenta em sua oração a Deus, numa preparação para o encontro com seu irmão Esaú: "Eu, teu servo, não mereço toda a bondade com que me tens tratado. Quando atravessei o rio Jordão, eu tinha apenas um bastão e agora estou voltando com estes dois grupos de pessoas e animais" (Gn 32.10).

Torna-se evidente que alguma mudança já estava acontecendo. Ele reconhece a bondade de Deus e sua dependência Dele. Deixa de lado o orgulho de inflação que poderia levá-lo a pensar que seu sucesso se devia unicamente à sua capacidade e astúcia, reconhecendo a presença e a própria existência de Deus, ou seja, passa a se ver e se posicionar no mundo de uma forma mais humilde.

Mas por que precisa voltar? A jornada do herói, que se iniciou quando deixou a casa de seus pais, agora pode ser completada com seu regresso para casa. Trata-se de um ciclo que precisa ser fechado.

Esta volta tem um sentido especial na medida em que pode reparar coisas do passado que ficaram em aberto. Especialmente no que se refere a seu irmão Esaú.

Ele então se coloca a caminho com as suas esposas, seus filhos e seus rebanhos. Chega ao vale do Jaboque, as pessoas passam, mas Jacó fica sozinho, para trás.

Um vale é um local bem especial, indica emoções deprimentes (Hilmann, 1988, p. 209). Sugere um mergulho na escuridão da alma, diferentemente dos picos, habitados pelo espírito.

A realidade dos picos e vales é tratada de forma poética e profunda em uma carta do Décimo Quarto Dalai Lama do Tibet a Peter Goulart, citada por Hilmann (1988, p. 210). 
A relação entre altura e espiritualidade não é apenas metafórica. É uma realidade física. As pessoas mais espirituais deste planeta vivem nos lugares mais altos. À semelhança das flores mais espirituais... Chamo de espírito aos aspectos mais leves e elevados de meu ser e de alma ao mais escuro e pesado. A alma acha-se em casa nos vales profundos e sombrios. Pesadas flores entorpecidas, saturadas de negro, crescem ali. Os rios fluem como xarope quente. Desembocam em enormes oceanos de alma. O espírito é uma região de brancos e elevados picos, de lagos e flores cintilantes como jóias. A vida é escassa e os sons viajam grandes distâncias. Existe música da alma, alimento da alma, doença da alma, e amor da alma... Quando a alma triunfou, os pastores vieram ao convento dos lamas, pois a alma é comunitária e gosta de ladainha em uníssono. Mas a lama criativa anseia pelo espírito. Abandonando as selvas da lamaseria, os belos monges, um dia, dizem adeus a seus camaradas e iniciam sua jornada solitária rumos aos picos, para ali se unirem ao cosmo...Nenhum espírito faz choco sobre a soberba desolação; pois a desolação pertence aos abismos, como as ninhadas. Nestas altitudes, o espírito abandona a alma bem para trás. Criaturas humanas necessitam escalar a montanha não simplesmente porque ela se ergue à sua frente, mas porque a divindade plena da alma necessita unir-se ao espírito.

Aparece então um homem que começa a lutar com Jacó, viu que não poderia vencê-lo, dá um golpe e desloca a junta de sua coxa.

O homem pede que Jacó o solte. Este, porém, exige que o homem o abençoe. O homem pergunta o nome de Jacó, que responde, ele então conclui que a partir de agora o nome de Jacó passaria a ser Israel, pois Jacó lutou com Deus e com os homens e venceu. Por fim, o homem o abençoa.

Focalizando a questão da luta em si, Edinger (1990, p. 73) enfatiza que ela tem quatro elementos do que ele descreveu como arquétipo de Jó:

1 - Encontro com um ser superior

2 - Ferimento

3 - Perseverança

4 - Revelação divina

Em relação ao primeiro ponto, a Bíblia descreve que o rosto desse homem não podia ser identificado. Por ser à noite que se deu o embate, como também este detalhe da não identificação do oponente, é possível se pensar aqui numa figura do inconsciente, ou seja, a sombra.

A sombra diz respeito ao lado do indivíduo que ele prefere não revelar, segundo Jung, citado por Palmer (1997, p. 135) consiste em "Tudo aquilo que o sujeito se recusa a reconhecer sobre si mesmo e que, no entanto, está sempre se lançando sobre ele direta ou indiretamente - por exemplo, traços inferiores de caráter e outras tendências incompatíveis".

Na verdade, está se desenrolando aqui o que Jung denominou como processo de individuação, um dos pilares da teoria junguiana, que tem como meta e finalidade o desenvolvimento da personalidade individual.

Em Consciente, Inconsciente e Individuação, Jung fornece uma reflexão que ajuda a pensar sobre o que seria a individuação, quando diz que "a individuação significa tornar-se um "in-divíduo" e, na medida em que abarca nossa mais profunda, última e incomparável peculiaridade, a "individualidade" também implica que a pessoa se torne o que ela de fato é. Podemos, portanto, traduzir individuação como "chegada à condição de eu” ou "auto-realização". (Palmer, 1997, p. 183)

A individuação não é um ponto matemático, mas pode ser entendida como um processo que é inato aos indivíduos, é uma lei natural do psiquismo, é uma tarefa a qual todos os seres humanos precisam se dedicar, com graus diferentes de sucesso.

A individuação está voltada para a busca do equilíbrio psíquico, ou seja, a união dos opostos. Isso significa assimilar ou integrar à consciência as várias partes inconscientes da psique. Assim a individuação pede que o indivíduo se torne sensível e receptivo, consiga prestar atenção a aspectos do Si-mesmo que ele tem negligenciado, que deixou não desenvolvidos (Palmaer, 1997, p. 184). Esses aspectos podem ser de várias origens como coisas desagradáveis em si, ou seja, a Sombra, valores incompatíveis com sua Persona, padrões masculinos ou femininos inconscientes, atitude particular não dominante ou inferior.

É interessante reforçar que a individuação, conforme apresentada por Jung, é algo totalmente natural e espontâneo, com paralelo aos processos físicos de crescimento e envelhecimento (Palmer, 1997, p. 184). A personalidade destina-se a individualizar-se, mas há fatores como heredita- 
riedade, influências familiares, educação, ambiente, entre outras, que podem atrapalhar este processo. Dá, por exemplo, as barreiras e desafios que Jacó precisou enfrentar para conseguir se desenvolver, ou se individualizar.

Nesse sentido da luta de Jacó, o ponto de partida é uma união com o Si-mesmo, uma união caótica e indiferenciada. Há todo um processo de vida. A chegada é novamente um estado caótico, porém de integração onde o ego é capaz de ampliar sua consciência e percepção da realidade. $\mathrm{Na}$ verdade a posição do ego em si fica relativizada pela sua conciliação com o inconsciente. Essa integração total entre o ego e o Si-mesmo, apesar de ser um ideal de perfeição impossível de ser alcançado, pode ser buscada como meta.

Neste ponto, pode-se voltar ao segundo estágio do que foi colocado anteriormente sobre o arquétipo de Jó, que consiste no ferimento.

O encontro do ego com o Si-mesmo, na pior das hipóteses, pode levar à loucura, ou seja, à cisão ou aniquilamento do ego. Jung (1988, p. 292) comenta este perigo:

O processo de individuação constitui uma tarefa sumamente penosa, em que há sempre um conflito de obrigações, cuja solução supõe que se esteja em condições de entender a vontade contrária como vontade de Deus. Não é com meras palavras, nem com autoilusões cômodas que se enfrenta o problema, porque as possibilidades destrutivas existem em demasia. O perigo quase inevitável consiste em ficar mergulhado no conflito e, conseqüentemente, na dissociação neurótica.

Ao se abordar o ferimento de Jacó, voltase ao estado de inflação de Jacó, estando possuído pelo que os gregos chamavam de hybris, ou seja, Jacó foi além dos seus limites.

Agora, na luta com Deus e especialmente no fato de ter sido ferido, observa-se a conseqüência da hybris, a saber, o que os gregos chamavam de Nêmesis, que é a reação dos deuses justamente para tirar o herói deste seu orgulho e leválo a uma atitude de humildade e respeito, ou seja, de piedade (Edinger, 1972, p. 58).

Ainda sobre o ferimento, é interessante destacar que o ego de fato sai machucado diante de um encontro tão violento com o numinoso. Um detalhe a ser valorizado é a necessidade de Jacó, a partir de agora, ser obrigado a mancar.
Como era Jacó antes do embate? Talvez altivo, bem-sucedido, senhor de si. Ao ter que mancar ao andar, Jacó passa a ter que baixar a cabeça. É comum na sabedoria popular ouvir: "O fulano não é de baixar a cabeça para ninguém”, ou seja, é uma pessoa orgulhosa.

Assim, depois da luta e do ferimento, Jacó passa a ter um ganho importante no que diz respeito à postura física que reflete sua postura espiritual: Jacó reconhece que há alguém mais poderoso e maior do que ele. O ego não mais está identificado com o Si-mesmo, mas consegue se diferenciar e reverenciar o Si-mesmo.

Sobre o $3^{\circ}$ estágio do arquétipo de Jó, que Edinger chama de perseverança, pode-se pensar, como em todo o processo de individuação, o esforço do ego.

O $4^{\circ}$ e último estágio, a Revelação Divina, envolve o estágio final do desenvolvimento, onde uma mudança efetiva acontece em Jacó. Aliás, a mudança é tão profunda que se modifica algo que é o grande diferencial entre as pessoas, o nome. Jacó recebe um novo nome, Israel, agora está pronto para ser um patriarca do povo escolhido de Deus.

No final da luta, onde Jacó se portou muito bem e heroicamente enfrentou Deus, quando Jacó teve seu nome mudado, vem o pedido final: a bênção. O homem, por fim, abençoa Jacó.

Da contenda, da luta, do enfrentamento, é possível imaginar agora a paz, uma conciliação. $\mathrm{O}$ ego enfrentou o Si mesmo, colocou em risco a sua integridade e existência, mas sai abençoado.

Agora, Israel, antigo Jacó, estava pronto para a prova final, para o encontro final com seu irmão Esaú que concluiria esta importante etapa de sua vida.

Considerando o sucesso que Israel teve em se desenvolver, o encontro não poderia ter sido melhor: os irmãos se abraçaram e choraram juntos e puderam viver em paz.

Na vida, porém, jamais uma história termina por completo, pois na medida em que uma termina, outra está começando.

Jacó teve 12 filhos com suas quatro esposas. Se antes a história estava focada em indivíduos, agora ela passa para a coletividade (Edinger, 1990, p. 76).

Se Jacó foi o escolhido de sua mãe e de Deus, ele e Deus escolhem o filho José, que passa a ser o sucessor do herói. Ele agora é o herói que 
vai ser vendido, ou seja, o herói parte, vai passar por provas e dificuldades e finalmente ser o vencedor. A história continua, o caminho da individuação nunca termina.

\section{Conclusão}

Alguns passos importantes que Jacó conseguiu dar no seu processo de desenvolvimento pessoal estão presentes ainda hoje na vida humana, notadamente em se tratando do masculino.

Sendo assim, torna-se ilustrativo um levantamento de como Jacó lidava com certas situações quando ainda estava num grau menor de desenvolvimento e como passou a levar a vida de forma diferente a partir de seu crescimento pessoal.

O nascimento de Jacó já é ilustrativo: nasce "pegando no pé do irmão" e recebe o nome de "enganador". O Jacó individuado não pega mais no pé do irmão, deixou de levar sua vida com enganação, astúcia e "jeitinhos", mas tem uma atitude de maturidade no final da história, quando fecha o círculo da vida, ou seja, volta para corrigir o que estava errado, volta para se reconciliar com seu irmão. Seguindo uma lógica interessante, não volta mais como "o enganador", mas tem seu nome mudado, tem sua vida completamente modificada.

Na primeira fase de sua vida ele está completamente identificado com a mãe. É o "queridinho da mamãe", a mãe o domina, determina o que deve fazer para enganar o irmão. Soa até um pouco incomum para a época o fato de Jacó ficar em casa com a mãe, enquanto seu irmão saia de casa para caçar.

Ao ser forçado a sair de casa, fugir, é obrigado também a se desenvolver, a crescer, a adquirir uma série de competências e habilidades pessoais.

Aprende a se virar no deserto, num curso de sobrevivência, passa a ter que cuidar de si.

Aprende a lidar com o mundo dos negócios, trabalhando para o tio, sendo enganado por ele, tendo a sabedoria de reverter a situação. Não há mais lugar para um menino ingênuo, cujo pai ou empregados cuidavam de tudo. O Jacó maduro se torna um habilidoso executivo que administra com destreza seus negócios pessoais.

Aprende a lidar com a vida amorosa. Em casa, possivelmente, a sua mãe teria escolhido uma esposa a qual ela teria julgado adequada para ele. O Jacó em processo de individuação escolhe a esposa, é enganado, e tem a perseverança necessária de um homem maduro, o que não pertence ao mundo infantil, de lutar e trabalhar mais sete anos pela sua querida, quatorze ao todo, haja amor.

Ainda hoje é possível observar muitos Jacós com grande potencial de se aventurar pelos desertos da vida para conquistar independência financeira, o amor maduro de uma mulher ou se virar com coisas práticas da vida (contas, roupas, saúde, etc.), mas que, infelizmente, ficam presos à tutela de uma mãe dominadora. Mãe aqui pode ser pensada como mãe mesmo ou como uma situação cômoda e confortável, que faz com que o herói, em vez de ir, fique.

Nos caminhos da individuação, percorridos por Jacó, o episódio do sonho também é muito ilustrativo.

Até aqui, observa-se em Jacó uma atitude um tanto narcisista, voltando apenas para si e seus interesses. Possuído pela hybris, tenta tomar o lugar de Deus e resolver a situação: garantir seu direito de primogenitura.

Imediatamente antes do sonho, Jacó começa a fazer uma espécie de mergulho em sua alma e tem a sua primeira grande experiência religiosa.

O "velho" Jacó só confiava em si e na astúcia que tinha. O "novo" Jacó começa a reconhecer a necessidade de um relacionamento com Deus. Jacó experimenta Deus na visão dos anjos e na voz que o abençoa. Depois disso, faz uma promessa de fidelidade a Deus. Não está mais autocentrado, mas neste mergulho em sua alma, vislumbra realidades profundas que precisam ser reconhecidas e integradas.

Nesse sentido, as operações alquímicas relacionadas ao sonho colaboram para uma melhor compreensão.

Por um lado, no seu desenvolvimento pessoal, Jacó precisa sair do senso comum, precisa sublimar, colocar-se para o "alto", mais perto de Deus, rever sua escala de valores. Isso aconteceu, por exemplo, na retomada do relacionamento com Esaú. Um menino fujão, e ainda por cima rico, não teria motivo algum para voltar. Um homem, porém, mudado, transformado, desenvolvido pela vida, retoma questões que ficaram em aberto.

Por outro lado, Jacó também precisa coagular uma série de coisas em sua vida. É significativo o episódio do casamento, quando por estar em excessiva sublimatio, ou seja, bêbado, "alto", 
foi enganado. É possível se pensar numa situação que até hoje se manifesta de uma postura juvenil inconseqüente de farras, bebedeiras, irresponsabilidade. Jacó pagou caro por sua irresponsabilidade, sete anos de trabalho. Qual o preço que muitos jovens pagam? Às vezes a própria vida.

A coagulação vem dar a Jacó a maturidade de ter "os pés no chão", a densidade, concretude, consistência de um homem, que normalmente faltam a um menino.

Finalmente o grande momento, o ápice, a luta de Jacó com Deus.

Jacó já demonstra um desenvolvimento pessoal marcante ao se colocar e enfrentar a situação. Uma postura infantil ou imatura seria enganar, fugir, evitar encarar de frente uma situação que cause ansiedade.

Nada mais favorável ao desenvolvimento pessoal que uma luta com o Si-mesmo, com aspectos sombrios reprimidos. A luta é dura, dolorosa, leva a eternidade de uma noite toda, o que poderia significar uma vida toda.

Ainda hoje as marcas da luta podem aparecer numa depressão violenta, numa doença, num acidente, numa ruptura familiar trágica. A via do ferimento pode ser extremamente dolorosa. Tal como os animais, porém, que lambem suas feridas, e podem transformá-las em minas de sal, o sofrimento pode ajudar a salgar a vida, a dar gosto, a amadurecer, a preparar para o que há de vir. Nesse sentido, não é incomum encontrar pessoas que após um evento trágico em suas vidas mudaram radicalmente sua forma de viver.

Jacó tem seu nome mudado para Israel, aquele que luta com Deus. Na verdade o vale do rio Jaboque tem um sentido de batismo para Jacó, onde o velho homem é afogado e o novo surge glorioso, como na tradição do Batismo cristão. O velho Jacó, com a vida cheia de jeitinhos, enganações, orgulho, auto-suficiência, é afogado. Surge agora Israel, marcado pela ferida, humilde, temente a Deus, pronto para se reconciliar com seu irmão Esaú. Pena que muitos Jacós de hoje não vivem ou se desenvolvem o bastante para experimentar essa mudança.

Por fim, Jacó se reconcilia com seu irmão. Nota-se aqui num aspecto social do processo de individuação. A pessoa que se desenvolve não guarda isso para si, mas quem convive com ela vai sentir as conseqüências e marcas positivas deste desenvolvimento. Jacó agora pode fechar algo que ficou em aberto. Quantas coisas estão em aberto na vida dos
Jacós de hoje que clamam por uma solução ou um encaminhamento? Havia também um aspecto teleológico na história de Jacó que foi contemplado, Jacó precisa voltar para cumprir seu destino, e voltou.

Mas a história não termina, o eterno ciclo da vida continua quando José, filho preferido de Jacó, começa a aparecer como sucessor do pai e empreende uma fuga forçada para o Egito. O processo jamais acaba, o ciclo começa, termina e começa novamente, é o eterno uruboros se fazendo presente.

\section{Referências}

Bíblia Sagrada (2000). Nova tradução na linguagem de hoje. Barueri: Sociedade Bíblica do Brasil.

Edinger, E. (1972) Ego e arquétipo. São Paulo: Cultrix.

Edinger, E. (1990) Bíblia e psique. São Paulo: Paulinas.

Grinberg, L. P. (1997) Jung- o homem criativo. São Paulo: FTD.

Hillman, J .(1988) O livro do puer- ensaios sobre o arquétipo do Puer Aeternus. São Paulo: Cultrix.

Judy, D (1992). Curando a alma masculina. São Paulo: Paulus.

Jung, C. G. (1965). Psicologia e religião. Rio de Janeiro: Zahar.

Jung, C. G. (1988). Psicologia da religião ocidental e oriental. Petrópolis: Vozes.

Jung, C. G. (1994). Psicologia e alquimia. Petrópolis: Vozes.

Jung, C. G. Mysterium Coninctionis. Petrópolis: Vozes.

Jung, C. G. (1996). 0 eu e o inconsciente. Petrópolis: Vozes.

Jung, C. G. (1997). A energia psíquica. Petrópolis: Vozes.

Palmer, M. (1997). Freud e Jung sobre religião. São Paulo: Loyola.

Recebido em/received in: 12/02/2007 Aprovado em/approved in: 15/02/2007 